\section{Praxis-Poiesis: fundamentos, reflexões e ações de um projeto de extensão universitária em Terapia Ocupacional}

\author{
Praxis-Poiesis: foundations, reflections and actions of \\ an university extension project in Ocupational Therapy
}

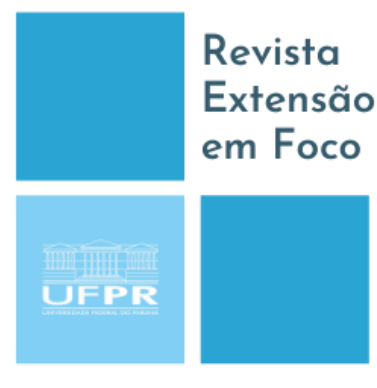

ISSN $2358-7180$

Adriana Belmonte Moreira ${ }^{1}$, Ana Beatriz Zimmermann², Lauren Machado Pinto ${ }^{3}$

\author{
RESUMO
}

O projeto de extensão "Praxis-Poiesis: cotidiano, convivialidade e modos não convencionais de vida" vinculado ao Departamento de Terapia Ocupacional da Universidade Federal do Paraná - UFPR, surgiu da necessidade de criar espaços de reflexão-ação conjunta sobre o cotidiano e o modo de vida capitalístico, a partir da afirmação da diversidade da vida. Categorizado na área temática Direitos Humanos e Justiça, ele foi voltado a profissionais terapeutas ocupacionais dos serviços conveniados aos Cursos e demais interessados; pessoas vinculadas grupos e coletivos organizados de defesa de direitos e populações específicas, como de pessoas em situação de rua, pessoas com deficiência, usuários de serviços de saúde mental, LGBTQIA+, entre outros. Na experiência, como perspectiva teóricoconceitual, adotou-se os pensamentos de Lukács, Heller, Lefebvre, Certeau, Maffesoli, Latouche e Illich. Foram utilizadas estratégias e recursos de caráter narrativo e participativo, de orientação hermenêuticodialética. Foram realizadas 13 ações, com 146 participantes. Como resultados, os participantes relataram maior proximidade com a natureza e seus ritmos, o maior respeito à diversidade da vida e atitudes orientadas ao bem-viver na casa comum. Além disso, identificaram as estratégias e recursos metodológicos utilizados como replicáveis em suas ações profissionais, em contextos clínicoassistenciais, educativos, culturais e sócio-comunitários. Como esperado inicialmente, o projeto colaborou para a formação crítico-reflexiva dos participantes, a interação dialógica entre diferentes grupos, e proporcionou o aprofundamento de conteúdos relativos às atividades e recursos terapêuticos, ministrados pelas coordenadoras do projeto, colaborando com a implementação do projeto pedagógico dos Cursos de Terapia Ocupacional.

Palavras-chave: Terapia ocupacional/educação. Terapia ocupacional/ética, atividades cotidianas. Direitos Humanos. Extensão Universitária.

\title{
ABSTRACT
}

The extension project "Praxis-Poiesis: everyday life, conviviality and nonconventional ways of life" associated to Occupational Therapy Department of Federal University of Paraná, arouse out of the need to create spaces for joint reflection-action about daily and capitalistic way of life, based on the affirmation of the diversity of life. Categorized in the thematic area Human Rights and Justice, it was

\footnotetext{
${ }^{1}$ Doutora em Filosofia. Docente do Departamento de Terapia Ocupacional da Universidade Federal do Paraná - UFPR, Curitiba/Paraná, Brasil. E-mail: adriana.belmonte@ ufpr.br. Orcid: http://orcid.org/00000002-8509-0425

${ }^{2}$ Mestre em Saúde, Interdisciplinaridade e Reabilitação. Docente do Departamento de Terapia Ocupacional da Universidade Federal do Paraná - UFPR, Curitiba/Paraná, Brasil. E-mail: anabeatriz@ufpr.br. Orcid: http://orcid.org/0000-0002-0977-338X

${ }^{3}$ Mestre em Medicina Interna e Ciências da Saúde. Docente do Departamento de Terapia Ocupacional da Universidade Federal do Paraná - UFPR, Curitiba/Paraná, Brasil. E-mail: 1auren.machado@ufpr.br.Orcid: https://orcid.org/0000-0002-3103-3206
} 
aimed at professional occupational therapists from the services associated with the Courses and other interested parties; people linked to groups and collectives organized to defend rights and specific populations, such as homeless people, people with disabilities, users of mental health services, LGBTQIA+, among others. The ideas of Lukács, Heller, Lefebvre, Certeau, Maffesoli, Latouche and Illich were adopted as a theoretical-conceptual perspective during the project experience. Narrative and participatory strategies and resources were used guided by a hermeneutic-dialectic approach. The 13 actions were carried out with a total of 146 participants. As a result, the participants reported greater proximity to nature and its rhythms, greater respect for the diversity of life and attitudes oriented to wellbeing in the common home. In addition, they identified the strategies and methodological resources used as replicable in their professional actions, in clinical-care, educational, cultural and socio-community contexts. As initially expected, the project collaborated with the critical-reflexive formation of the participants, the dialogical interaction between different groups and favored deepening the contents of activities and therapeutic's resources conducted by the project coordinators which cooperated with the implementation of the pedagogical project of Occupational Therapy Courses.

Keywords: Occupational therapy/education. Occupational therapy/ethic, activities of daily life. Human rights. University Extension.

\section{INTRODUÇÃO}

O projeto de extensão universitária intitulado "Praxis-Poiesis: cotidiano, convivialidade e modos não convencionais de vida" foi desenvolvido no período de 01 maio de 2017 a 30 de abril de 2018, sob coordenação de três docentes e participação de 04 extensionistas dos Cursos de Terapia Ocupacional (integral e noturno) da Universidade Federal do Paraná - UFPR, situada na cidade de Curitiba. Categorizada na área temática Direitos Humanos e Justiça, a proposta foi voltada a profissionais terapeutas ocupacionais dos serviços conveniados aos Cursos e demais interessados; pessoas vinculadas grupos e coletivos organizados de defesa de direitos e populações específicas, como de pessoas em situação de rua, pessoas com deficiência, usuários de serviços de saúde mental, LGBTQIA+, entre outros.

O projeto nasceu com a finalidade de criar um espaço de reflexão-ação conjunta sobre cotidiano, convivialidade, formas e modos não convencionais de vida, através de metodologias narrativas e participativas, de orientação hermenêutico-dialética, tendo em vista que proposições metodológicas desta natureza têm como principal característica a valorização de experiências e saberes pessoais e coletivos e têm como pressuposto a implicação direta dos envolvidos no processo de reflexão na produção de conhecimento e nas ações práticas derivadas da reflexão-ação conjunta (MOREIRA; PINTO, 2018).

Dada a centralidade do cotidiano na formação e prática do terapeuta ocupacional, partiu-se de uma perspectiva do campo profissional, porém com valorização do diálogo interdisciplinar na área das Humanidades. Considerou-se que as noções de cotidiano e convivialidade têm sido estudadas pelos terapeutas ocupacionais (FERIGATO et. al., 
2016; GALHEIGO, 2003), servindo ao projeto como conceitos-chave para orientar as ações propostas. Levou-se em conta também as experiências de utilização de atividades e recursos estéticos nos processos formativos em Terapia Ocupacional (CASTRO et. al., 2009; FURTADO; FISCHER, 2011; SILVA; POELLNITZ, 2015).

Com isso, almejava-se lançar diferentes olhares sobre os modos de vida cotidianos, entendidos como diferentes maneiras de viver tecidas em meio a exercícios éticos, no bojo de processos culturais coletivos, bem como para as táticas voltadas à participação social e aos bons conviveres (ACOSTA, 2016), pensando sobre nossas ações enquanto estudantes, profissionais e docentes no que tange à afirmação da diversidade e no enfrentamento a barreiras e processos de exclusão sociopolítica e cultural de grupos específicos atendidos pelos terapeutas ocupacionais.

O projeto teve por ideia-força matriz a alegria partilhada pelo bem-viver na casa comum (Figura 1), e a noção de vida como potência (MOREIRA, 2010), compreendida em suas tramas material, afetiva e relacional e, sobretudo, em sua diversidade de formas e em sua capacidade de (re)criação normativa e de resistência/resiliência em todos os âmbitos em que se efetiva. Nota-se que foi adotada uma concepção ampliada de vida (physis), que inclui a natureza em seu conjunto, o vivente humano e o não-humano, a Terra em sua totalidade natural e cultural, em uma visão articulada entre os Direitos humanos e os Direito da natureza (ACOSTA, 2016).

Figura 1 - Logotipo do Projeto

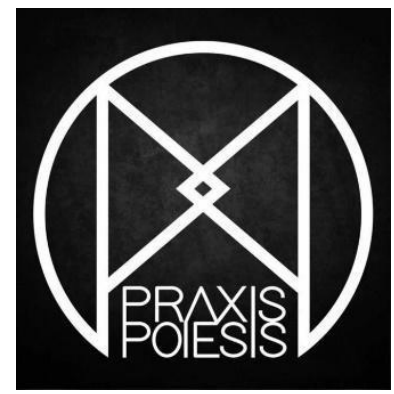

Fonte: Acervo de imagens do projeto

Ele tinha, portanto, por intencionalidade, o aumento da potência de agir individual e coletiva dos participantes a partir do campo da experiência cotidiana e dos saberes advindos dela (BONDIA, 2002). Pois, como bem notam Fonseca et. al. (2018) seguindo o conceito de experiência liminar de Benjamin, é possível cuidar da experiência, despertar potências originárias em estilos de vida capazes de suportar e recriar o cotidiano que nos 
assedia e nos obseda, apostando no valor da experiência e em sua comunicabilidade narrativa, imagética, como um meio de se contrapor à barbárie e reinventar o tempo presente (FONSECA et.al.; 2018).

Com efeito, Galheigo (2003, p. 108) afirma que o uso do conceito de cotidiano traz implícita uma mudança radical na proposição teórico metodológica da Terapia Ocupacional, pois "funda-se na retomada histórica e contextualizada do sujeito e sua inserção participante no coletivo”. Da conjugação das leituras filosóficas e sociológicas críticas realizadas por autores como Lefebvre, Lukács e Heller e representantes da sociologia da vida cotidiana, de tradição interpretativa e cultural, emerge a ideia de ressignificação crítica do cotidiano, que consegue contemplar tanto a estrutura da vida cotidiana quanto os sujeitos produtores de significação e da realidade histórico-social.

O cotidiano, como elemento que edifica o macro sistema histórico-social, pode ser visto a partir da trama de relações intersubjetivas e convivais, da aura do imaginário partilhado, das pequenas histórias e utopias no bojo da vida comum, que tecem as formas de socialidade, o estar-junto e a integração com o ambiente natural circundante (MAFFESOLI, 2010a; 2010b). Frente à ordem econômica dominante, as artes e maneiras de fazer podem também tornar-se operações minúsculas e cotidianas que jogam com o instituído, configurando uma maneira de pensar e de agir criativa, dispersa, tática e bricoladora (CERTEAU, 2014).

Portanto, compreendendo o cotidiano como alvo de crítica e de alavanca para mudanças e transformações pessoais e estruturais, pode-se dizer que, ainda que marcado por repetições, uniformizações, normalizações, é também através do cotidiano que se consegue erodir o status quo, através das táticas de resistência/resiliência éticas, estéticas e políticas e da afirmação da diversidade das formas e modos de vida. Pois, se por um lado o cotidiano pode ser alvo de crítica, pois é nele que se reproduzem as relações e alienações sociais, próprias ao sistema capitalista, dele também podem emergir micro resistências, nas formas de uso de objetos e do tempo, na apropriação de espaços e nas relações com os outros.

Destarte, por uma vertente propositiva, a crítica ao modo de vida cotidiano contemporâneo capitalístico precisa passar pela adoção de perspectivas ético-políticas outras, caminhando na direção de uma estilística da existência no contexto de uma arte de viver, da ampliação de territórios existenciais ético-estéticos e político-sociais, em uma atitude de disponibilidade e de abertura à diferença capaz de operar 
resistências/resiliência aos dispositivos biopolíticos e às injunções uniformizantes, disciplinares e normalizadoras dos modos de vida considerados não convencionais, desviantes ou anormais (FOUCAULT, 2000, 2008; PASSOS; BARROS, 2004).

\section{COTIDIANO EM PERSPECTIVA PRÁXICO-POIÉTICA}

A práxis, na medida em que pode vir a ser atividade crítico-prática, envolve ao mesmo tempo objetividade e subjetividade, traduzindo processos de transformação da natureza, do mundo histórico-social e do homem em si mesmo. Podendo ser, por esta mesma faceta, revolucionária, há nela uma dimensão poética, identificada à liberdade de criação sócio-histórica, própria a sujeitos autônomos, advinda da atividade da imaginação criadora e do imaginário radical (CASTORIADIS, 1982). Destarte, se a política se coloca em relação direta com a ética e com a estética (HERMANN, 2005), é porque os processos histórico-sociais também se sustentam através de ideias, afetos, valores e sensibilidades, postos em circulação, sedimentados e reproduzidos na vida cotidiana.

De modo mais preciso, enquanto atividade prática do homem diante dos conflitos e contradições no âmbito da sociedade, a práxis, pode ser criativa - incluída sua faceta crítica e revolucionária - ou reiterativa (imitativa), podendo ter caráter espontâneo ou reflexivo de acordo com seu grau de consciência (VAZQUEZ, 1977). Por essa perspectiva, sob os mecanismos de alienação na sociedade capitalista, o cotidiano tende à mera reiteração irrefletida; tendo nele pouco espaço para o engendramento de processos criativos, críticos e de resistência política.

Com efeito, agindo sobre as diferentes dimensões da vida cotidiana, o sistema capitalista, pelo viés específico que a proposta extensionista partiu, opera a partir de convenções e de imposições - estéticas (ideal de corpo, sensação e expressão), de uso dos objetos (consumo, desinvestimento afetivo, padronização); relacionais (competitividade, hierarquias, egoísmo e interesses) e de regulação do tempo-espaço (ritmos acelerados, instantaneidade, formas de organização e de acesso a espaços); fazendo dela um locus de reprodução das relações hierárquicas e desiguais de classe, competitivas e pouco amicais reforçadas pelas vivências no mundo do trabalho e pela privação do acesso à cidade, da produção/fruição cultural e das barreiras à articulação/mobilização social. 
De acordo com Lukács apud Costa (2001), as ações cotidianas são caracterizadas pela heterogeneidade, imediaticidade, superficialidade extensiva e pelo materialismo espontâneo e são reprodutoras da normalidade da vida de cada indivíduo, servindo para que ele funcione bem no seu dia-a-dia. Como resultado do conformismo, o homem se orienta na cotidianidade pelo simples cumprimento adequado de seus papéis e permanece imerso na sucessão heterogênea das atividades cotidianas.

Qual então a possibilidade da vida cotidiana, tornar-se motora de transformações globais, considerando que estamos imersos no mundo moderno capitalista, em seu tempo/espaço de produção e consumo? (NETTO; CARVALHO, 2007).

Para Lefebvre apud Netto e Carvalho (2007), o cotidiano é um espaço modelado pelo Estado e pela produção capitalista e os modos de vida são homogeneizados de modo a diminuir as possibilidades de liberdade, ainda que intersticiais. Em suas dimensões (trabalho, família e lazer), ele assume uma significação política e somente pela via da crítica ao modo de vida burguês haveria o alargamento das possibilidades de realização concreta das potencialidades humanas, acenando para um horizonte real de mudança (LACOMBE, 2008).

Todavia, de acordo com Heller (2004), a vida cotidiana não é alienada em consequência de sua estrutura, mas em determinadas condições sociais. Assim, para rompermos os processos alienantes do cotidiano é necessário que quebremos a rotina, a repetição e a regularidade da rígida ordem da cotidianidade, criemos uma entonação própria a nosso redor e orientemos nossas ações pela lógica da solidariedade, a partir de novas formas de expressão e de condução da vida cotidiana (HELLER, 2004; VANALI, 2015).

Há, portanto, formas de suspensão da vida cotidiana, a partir das quais o sujeito singular se percebe genérico e partícipe de uma totalidade, inserido em um coletivo maior, para o qual pode direcionar inteiramente suas forças (HELLER, 2004). A partir de uma boa distância da sucessão rotineira e monótona de tarefas, é possível tanto a percepção das mistificações simbólicas e manipulações afetivas, intelectuais, técnicas e políticas, quanto a apreensão da dimensão poiética da práxis, criadora, rítmica e material, constitutiva da dinâmica da vida social (LANTZ, 1992).

Igualmente afirmando essa possibilidade de escape das injunções capitalistas, Certeau (2014) reconhece a existência de redes de antidisciplina, como resistência à 
inércia e às imposições sociais, e que são materializadas nas diversas maneiras de fazer nas práticas cotidianas. Das artes de fazer (ler, falar, cozinhar, fazer compras, caminhar, habitar etc.), podem emergir táticas (ruses), traduzidas por manobras, estratagemas, trampolinagens, caracterizadas como bricolagens, patchworks do cotidiano, em oposição aos usos e costumes, marcados pela estereotipia e pela massificação social, cultural, científica etc. (CERTEAU, 2014, SOUZA FILHO, 2002).

Partindo de uma perspectiva de imersão na cotidianidade, para Maffesoli (2010a) há uma dimensão afetiva e relacional presente na vida comum; uma poiética cotidiana, baseada em uma ética de feição estética, com valorização do corpo, da imaginação, das emoções e afetos, na qual as experiências partilhadas podem ser vistas com abertura para a estesia corpórea, para a contemplação do belo e do fantástico em todas as coisas, pressuposto para a (re)vitalização dos fazeres e das relações cotidianas, em uma atitude de reencantamento do mundo.

A partir da crítica da sociedade moderna baseada na produção, no individualismo, no progresso e na dominação da natureza, identifica o surgimento de um ideal comunitário, baseado na solidariedade e na generosidade, segundo o qual é possível adotar outros modos de agir e de perceber os objetos e inventar novas formas de socialidade e de relação com a natureza; fundada em uma sensibilidade ecológica, na sabedoria de retorno à Terra, no território partilhado, no estar-junto com os demais viventes (MAFFESOLI, 2010b).

Desta forma, as diferentes maneiras de agir e fazer na vida cotidiana, as formas de apropriação de discursos e os usos dos objetos e utensílios tecem modos de vida, tendem em alguma medida ou ao rompimento ou à reprodução das relações sociais e de poder e da ética capitalística, egoística e competitiva. Em direção contrária, uma sociedade convival mostra que é possível tecer novamente os laços sociais e reintroduzir a philia (amizade) em contraponto a lei da selva e as disjunções da sociedade de crescimento (GUAJARDO, 2010, LATOUCHE, 2012)

Dada a homogeneização progressiva, a colonização do imaginário, o desenraizamento cultural e a estandardização das relações pessoais na sociedade capitalista, há que se criar opções de vida digna e sustentável, através da utilização limitada de recursos e de ferramentas tecnológicas e da criação de organizações convivais que estimulem a diversidade de modos de vida construídos coletivamente em meio a 
exercícios éticos, que não sejam a reedição caricaturizada do estilo de vida ocidental (LATOUCHE, 2006, 2012, GAJARDO, 2010).

Considerando os limites da natureza diante do consumo desenfreado, o programa do decrescimento aposta na possibilidade de se construir uma sociedade mais ecológica e socialmente mais justa e mais democrática, uma sociedade de abundância frugal baseada na autolimitação das necessidades criadas pela lógica industrial, consumistamercadológica; caminhando na direção de uma dinâmica de decrescimento convival e sereno (LATOUCHE, 2012).

\section{O PROJETO E SUAS ORIGENS}

O projeto assentou suas bases teórico-metodológicas no Curso de extensão ocorrido entre os meses de setembro a novembro de 2016, com 12hs de duração, intitulado "Perspectivas sobre o cotidiano, formas e modos não-convencionais de vida", o qual teve 18 participantes, entre eles, docentes, profissionais terapeutas ocupacionais e estudantes dos Cursos de Terapia Ocupacional da UFPR (MOREIRA; ZIMMERMANN, 2017).

O curso objetivou realizar, de modo introdutório, estudos sobre o cotidiano e sobre as formas e modos não convencionais de vida, e suas possibilidades de investigação a partir da orientação hermenêutico-dialética, compreendendo que esta diretriz, mais do que um método de tratamento de dados, por possibilitar uma reflexão fundada na práxis, é uma abordagem fecunda na condução do processo ao mesmo tempo compreensivo e crítico de análise da realidade social (MINAYO, 2002).

A matriz teórico-conceitual do curso foi os pensamentos de Heller, Certeau, Illich e Latouche. Explorou-se as ideias de revolução que explode e revolução que ocorre, aquela que se dá por mudanças gradativas no cotidiano, tentando responder aos seguintes questionamentos: quais as possibilidades da vida cotidiana ser motora de transformações? Quais táticas utilizamos cotidianamente, que nos possibilitam escapar do instituído? Quais são os nossos estilos de ação e sua entonação? Como criar espaços convivais e (re)inventar modos de pensar, agir, fazer e se relacionar operando resistências éticas, estéticas e políticas ao modo de vida capitalístico? 
Foi estudada ainda a orientação metodológica hermenêutico-dialética e utilizadas estratégias e recursos de caráter reflexivo-dialógico e participativo na condução do processo de ensino/aprendizagem, com apoio de recursos imagéticos e audiovisuais. Pois, a hermenêutica tem como categorias fundantes a compreensão, o significado, o símbolo, a intencionalidade e empatia; enquanto a dialética articula as ideias de crítica, de negação, de oposição, de mudança, de processo, de contradição, de movimento e de transformação da natureza e da realidade social.

Tal orientação têm como principal característica a valorização de experiências e saberes pessoais e coletivos e como pressuposto a implicação direta dos envolvidos no processo de reflexão, na produção de conhecimento e nas ações práticas derivadas. Para compreender o todo da experiência humana de mundo e da práxis da vida, ela possibilita a compreensão do sentido da comunicação, a linguagem narrativa escrita e falada como o terreno comum de realização da intersubjetividade e do entendimento, mas também da expressão da realidade conflitiva das desigualdades, da dominação, da exploração, conformismos e resistências (MINAYO In: MINAYO; DESLANDES, 2002; GOMES, 2014). Daí a orientação metodológica da proposta extensionistas de utilização de estratégias e recursos disparadores de reflexão-ação, narrativos e participativos, voltados a processos de mudança pessoal e transformação social.

Portanto, a construção coletiva do conhecimento sobre o tema estudado, procurou contribuir tanto para a formação acadêmica dos estudantes, quanto para o raciocínio teórico-prático do terapeuta ocupacional nos diferentes campos nos quais atua, procurando ainda abordar a diversificação das metodologias de pesquisa condizentes ao objeto de estudo profissional, procurando responder à questão: Como investigar e intervir em Terapia Ocupacional tendo o cotidiano por objeto de estudo e prática?

No decorrer do processo foram utilizadas estratégias e recursos metodológicos que incluíram momentos de exposição teórica, debate de ideias, registro vivencial de atividades e utilização de recursos audiovisuais com cenas do cotidiano, expressivos da vida e seus ritmos. Ao fim do curso, a avaliação positiva por parte dos participantes, a ressonância do processo partilhado e a necessidade de investir em espaços convivais para cultivar possibilidades de resistência/resiliência às normalizações cotidianas forneceram as bases para dar continuidade à proposta. 
Em vista disso, o projeto de extensão foi então concebido da ideia de que é a partir da dimensão sensível, poética e criadora das pequenas ações cotidianas que as mudanças pessoais e as transformações sociais são possíveis.

\section{O PROJETO E SUAS AÇÕES}

Dado isso, as ações do projeto privilegiaram as estratégias e recursos de caráter narrativo e participativo, de orientação hermenêutico-dialética, e colocaram ênfase no debate, identificação e criação de táticas de resistência/resiliência éticas, estéticas e políticas ao modo de vida cotidiano capitalístico, a partir da afirmação da diversidade das formas e dos modos de vida; em espaços de troca de saberes e experiências, baseados na convivialidade e no direito à cidade. Esperava-se, através dele:

a) Refletir sobre diferentes perspectivas sobre os conceitos de cotidiano e modos de vida para aprofundamento teórico e metodológico, com impacto na formação e nas práticas assistenciais;

b) Possibilitar a criação de espaços de encontro, orientados pelo princípio da convivialidade, com intuito de refletir e tecer nossos modos de vida cotidianos;

c) Gerar visibilidade às táticas de resistência/resiliência éticas, estéticas e políticas ao modo de vida capitalístico;

d) Possibilitar a apropriação dos espaços socioculturais urbanos, fomentando outros modos de transitar e habitar a cidade;

e) Promover a formação continuada, a interação dos discentes com os profissionais da rede parceira de serviços de saúde, socioassistenciais, de educação e cultura, justiça e cidadania e com membros de grupos e coletivos organizados de defesa de direitos de populações específicas, atendidas pelo terapeuta ocupacional (MOREIRA; PINTO, 2018).

Possibilitando diálogo e interações entre diferentes grupos - Universidade, serviços e sociedade organizada - as ações do projeto também se configurariam como uma estratégia disparadora de ações futuras por parte dos envolvidos, visto que as atividades propostas utilizadas poderiam ser realizadas em diferentes contextos, institucionais e comunitários, formais e informais. A aproximação de diferentes 
interlocutores, representativos de diferentes espaços e lugares sociais, reforçaria o sentido de abertura e trânsito entre diferentes formas de conhecer a realidade, entre saberes científicos e populares, oriundos da vida cotidiana em comum.

Assim, o projeto se justificou institucionalmente através da indissociabilidade ensino-pesquisa-extensão, pela relevância social de adotar uma perspectiva de efetivação de direitos de cidadania, garantidos pelas políticas públicas no âmbito sociocultural, e na importância de ações educativas voltadas ao enfrentamento de processos de exclusão social, de combate às barreiras sociais e à desigualdade de acesso que restringem oportunidades e vivências afirmativas e potencializadoras de pessoas, grupos e coletivos marcados pela diferença e pela vulnerabilidade.

O projeto procurou dialogar com os posicionamentos da World Federation of Occupational Therapists - WFOT sobre Direitos Humanos (2006), Diversidade e Cultura (2010) e Sustentabilidade Ambiental (2012), e os fundamentos éticos, bioéticos e teóricometodológicos da Terapia Ocupacional, incorporados no novo projeto pedagógico dos Cursos da UFPR e expressos em seus temas transversais, a saber: Ética, Justiça e Direitos Humanos; Diversidade étnico-racial e cultural; Territorialidade, desenvolvimento e sustentabilidade. E, mais especificamente com os conteúdos das disciplinas de Fundamentos para a prática profissional, Processos de Terapia Ocupacional e as de Atividades e Recursos Terapêuticos - ART (ZIMMERMANN et.al., 2019). Com isso, também almejava-se promover a associação das ações extensionistas com as atividades profissionais e de ensino, com enfoque em tendências contemporâneas nacionais e mundiais.

\section{ITINERÁRIO DE AÇÕES}

No período de vigência do projeto foram realizadas 13 ações, com o total de 146 participantes - considerando que alguns participaram em mais de uma ação - nas diferentes atividades: um Curso de extensão intitulado "Cotidiano, convivialidade e modos não convencionais de vida", dois eventos "Cinema e Cotidiano", oito Oficinas Criativas (Quadro 1), uma visita a equipamento sociocultural e um percurso urbano temático (MOREIRA; PINTO, 2018). Cada ação do projeto foi planejada de modo que os participantes tivessem uma experiência ético-estética e um despertar do imaginário, 
favorecendo uma reflexão crítica sobre o cotidiano, os modos de pensar, agir, sentir e se relacionar com os outros e a natureza, a partir de uma análise do modo de vida capitalístico. Além disso, que eles apresentassem suas próprias táticas de resistência ao modo de vida cotidiano normalizado e padronizado, em seus aspectos estéticos, de uso dos objetos, relacionais e de espaço-tempo, em larga medida próprio a vida nas grandes cidades.

O curso contou com 10 participantes e nele foram realizados estudos interdisciplinares sobre o cotidiano e sobre as formas e modos não convencionais de vida, a partir das biografias e pensamentos de Heller, Certeau, Latouche e Illich, e outras referências como Foucault e Bourdieu; de modo a explorar a relação dos modos de vida com as noções de habitus e microfísica dos poderes (BRAGA et. al., 2017; FOUCAULT, 2000). Além disso, manteve-se a orientação hermenêutico-dialética (MINAYO, 2002, GOMES, 2014) como diretriz da proposta.

Algumas das questões norteadoras dos encontros foram: Quem é o sujeito da vida cotidiana? Como ela se estrutura? Como se organiza o tempo-espaço, as ações práticas e a ética na vida cotidiana? Como os poderes modulam nossas disposições? Como construir modos de vida mais éticos e sustentáveis? Como despertar a capacidade de nos conectar consigo mesmo e com os demais seres viventes? Como criar espaços convivais e inventar modos de pensar, agir, fazer e se relacionar de forma a operar resistência/resiliência éticas, estéticas e políticas ao modo de vida capitalístico? Como tais elementos se aplicam na vida cotidiana de cada participante em um processo reflexivo pessoal?

No decorrer das atividades foram utilizadas estratégias e recursos de caráter reflexivo-dialógico e prático, colaborando para a construção coletiva do conhecimento sobre o tema estudado. A partir das reflexões, alimentadas por leituras prévias e fragmentos de texto dos autores de referência, foi proposto aos participantes que compusessem registros (visuais, orais e/ou escritos) de seus percursos e experiências cotidianas como possibilidade de expressão dos territórios vividos (modos de habitar de transitar), das formas e usos dos objetos (modos de fazer), das formas de se relacionar (modos de agir) e das mobilizações afetivas-corporais (modos de sentir).

Os eventos "Cinema e Cotidiano" contaram ao todo com 36 participantes e tiveram como proposta a apresentação de recurso audiovisual seguido de mesa de debate com coordenadoras e convidados. Nas ações propostas privilegiou-se a interação dialógica e participativa entre os presentes. Privilegiou-se também a abordagem 
interdisciplinar sobre o tema debatido, na interface do campo da Terapia Ocupacional com as humanidades (filosofia, sociologia, direito, psicologia, educação, artes, etc.).

No primeiro evento de Cinema, intitulado "Natureza, imaginário e resistência" foi apresentado o filme "Labirinto do Fauno" de Guillermo del Toro e realizado um debate com o Prof. Dr. Leandro Franklin Gorsdorf - Pró-reitor de Extensão e Cultura da UFPR. O debate foi centrado nos questionamentos sobre a relação entre os viventes humanos, a natureza e a sociedade, com foco no papel do imaginário para a resistência aos regimes totalitários, procurando responder: Quais as estratégias de depreciação e colonização do imaginário? Como reencantar o cotidiano através do imaginário? Qual a relação entre natureza, imaginário e resistência existencial e política?

No segundo evento, intitulado "Terapêutica, ética, estética e política", foram apresentados recortes de documentários de acesso aberto sobre o percurso biográfico da psiquiatra Nise da Silveira, seguido de mesa de debate com convidada terapeuta ocupacional Isabela Perotti da Associação Vida, Arte e Reinserção - ASSOVIAR. O debate versou sobre o posicionamento político de Nise da Silveira e suas referências conceituais, como Bachelard, Spinoza e Jung (MELLO, 2014), além de suas contribuições para a clínica terapêutico-ocupacional e para projetos emancipatórios para pessoas em sofrimento psicossocial; o que deu abertura para uma reflexão sobre a produção de saúde/doença em suas relações com o modo de vida cotidiano contemporâneo, e uma discussão sobre o papel das práticas de cuidado na atualidade.

Foi realizada ainda uma visita guiada ao Museu do Holocausto de Curitiba e um percurso urbano, contabilizando 31 participantes. A estratégia metodológica da primeira ação foi visita seguida de roda de conversa, e teve como objetivo de, através de um percurso em espaço da cidade, resgatar narrativas e reflexões sobre as relações humanas, deslocamentos e possibilidades de (re) organização em novos territórios. O foco do debate foi o extermínio de grupos minoritários e a violação dos direitos humanos, a capacidade de resistência/resiliência a partir das narrativas dos sobreviventes do Holocausto e da solidariedade dos "justos entre as nações". O objetivo principal da ação foi a reflexão ético-política sobre as intolerâncias nas relações cotidianas na atualidade e a importância da defesa da vida, sobretudo em tempos sombrios.

O "percurso 08 de março: cotidiano, gênero e política", teve por objetivo realizar uma reflexão-ação sobre a temática gênero, cotidiano e defesa de direitos das mulheres. A estratégia metodológica foi uma roda de conversa, mediada por atividades expressivas, 
gráficas e imagéticas reflexivas, seguida de acompanhamento da Marcha Mundial de Mulheres, que ocorria em Curitiba naquela data. Inicialmente foi apresentado uma reportagem-depoimento sobre Maria da Penha e, na sequência, realizada um debate a partir de dados sobre violência contra a mulher com tema "feminicídio e direitos". Após isso, foi realizada uma reflexão orientada por roteiro sobre temas: imposição estética; rivalidade feminina versus sororidade; casamento e maternidade; expectativas intelectuais e profissionais; sexualidade; e sobre estigmas/cobranças/desqualificações que incidem sobre a mulher no cotidiano e ações de resistência possíveis.

Além das ações acima relatadas, foram realizadas oito oficinas temáticas (Quadro 1), com 39 participantes ao todo, da comunidade UFPR e externa, profissionais de serviços da saúde, educação, assistência social e garantia de direitos, sem que alguns de se autodeclararam no momento da inscrição como partícipes de movimentos, coletivos de defesa de diretos (mulheres, negros, transexuais, pessoas em sofrimento mental, crianças e adolescentes em situação de vulnerabilidade), de arte e cultura urbanas e de associações culturais profissionais e de geração de renda e economia solidária.

Quadro 1- Oficinas temáticas e questões disparadoras

\begin{tabular}{|c|c|}
\hline Ações realizadas: & Questões disparadoras: \\
\hline $\begin{array}{l}\text { Oficina de Cartografia Corporal } \\
\text { Objetivou promover uma vivência } \\
\text { reflexiva de mapeamento corporal, } \\
\text { com ênfase nas relações e } \\
\text { experiências cotidianas }\end{array}$ & $\begin{array}{l}\text { O que (des)vitaliza o corpo nas experiências cotidianas? } \\
\text { Como se dá o despertar dos sentidos nas experiências } \\
\text { cotidianas? Qual trama de relações afetivas sustenta } \\
\text { minha vida cotidiana? }\end{array}$ \\
\hline $\begin{array}{l}\text { Oficina-Sarau: plantios poéticos } \\
\text { Objetivou promover uma vivência } \\
\text { coletiva de reflexão-ação sobre a } \\
\text { natureza e o cotidiano, através de uma } \\
\text { experiência poética de contato com a } \\
\text { terra. }\end{array}$ & $\begin{array}{l}\text { Qual a minha relação com a natureza e com os demais } \\
\text { viventes? Como minha relação com a natureza se articula } \\
\text { com as minhas ações/relações e a ética na vida cotidiana? } \\
\text { Qual a minha corresponsabilidade na garantia dos direitos } \\
\text { da terra, dos viventes humanos e demais viventes? }\end{array}$ \\
\hline $\begin{array}{l}\text { Oficina de Imaginário e } \\
\text { Criatividade Social } \\
\text { Objetivou promover uma vivência } \\
\text { coletiva de reflexão-ação sobre o } \\
\text { imaginário social, por uma } \\
\text { perspectiva ética, estética e política. }\end{array}$ & $\begin{array}{l}\text { Qual relação entre os elementos da natureza, o } \\
\text { imaginário e a resistência ético-política? } \\
\text { Que futuro sonho e quero para mim (individualmente) e } \\
\text { para os outros (coletivamente) e de que modo } \\
\text { orientamos nossas ações cotidianas nesta direção? }\end{array}$ \\
\hline $\begin{array}{l}\text { Oficina (re) usos: subversões de } \\
\text { objetos do cotidiano } \\
\text { Objetivou promover uma reflexão- } \\
\text { ação sobre os objetos e seus usos no } \\
\text { cotidiano, por uma perspectiva ética, } \\
\text { estética e política. }\end{array}$ & $\begin{array}{l}\text { Como os objetos e seus usos modulam nossas formas de } \\
\text { agir, querer e pensar no curso da vida cotidiana? Qual a } \\
\text { relação entre o consumo desenfreado e o descarte de } \\
\text { produtos e as relações humanas na contemporaneidade? }\end{array}$ \\
\hline $\begin{array}{l}\text { Oficina de Articulação } \\
\text { mobilização Social - } 1\end{array}$ & $\begin{array}{l}\text { Qual a importância da articulação e da mobilização } \\
\text { social para garantia de direitos humanos e fundamentais }\end{array}$ \\
\hline
\end{tabular}




\begin{tabular}{|c|c|}
\hline $\begin{array}{l}\text { Objetivo aproximar populações em } \\
\text { situação de vulnerabilidade aos } \\
\text { movimentos de defesa de direitos, } \\
\text { com foco no debate de gênero }\end{array}$ & $\begin{array}{l}\text { e para o enfrentamento das violências contra as mulheres? } \\
\text { Como operar micro e macro resistências a partir do } \\
\text { cotidiano e do engajamento em movimentos coletivos? }\end{array}$ \\
\hline $\begin{array}{l}\text { Oficina de Articulação } \\
\text { Mobilização Social - } 2 \\
\text { Objetivou aproximar populações em } \\
\text { situação de vulnerabilidade aos } \\
\text { movimentos de defesa de direitos, } \\
\text { com foco na inclusão social }\end{array}$ & $\begin{array}{l}\text { Qual o papel da arte e da cultura e movimentos de } \\
\text { resistência nas regiões periféricas? Como podem se } \\
\text { configurar como táticas para o enfrentamento de } \\
\text { exclusões e vulnerabilizações de adolescentes e jovens? }\end{array}$ \\
\hline $\begin{array}{l}\text { Oficina de Costuras Narrativas } \\
\text { Objetivou promover uma vivência } \\
\text { coletiva de reflexão-ação sobre } \\
\text { gênero, luta por direitos e estratégias } \\
\text { de resistência/resiliência no } \\
\text { cotidiano. }\end{array}$ & $\begin{array}{l}\text { Como pensamos na atualidade sexualidade, gênero e } \\
\text { orientação sexual? Quais resistências e resiliências na } \\
\text { vida cotidiana às hostilidades e intolerâncias à } \\
\text { diversidade? }\end{array}$ \\
\hline $\begin{array}{l}\text { Oficina de Vivências Elementais } \\
\text { Objetivou promover uma vivência } \\
\text { coletiva de reflexão-ação sobre a } \\
\text { natureza, sensibilidades, emoções e } \\
\text { afetos e as formas de resistência às } \\
\text { desensibilizações e alienações no } \\
\text { cotidiano. }\end{array}$ & $\begin{array}{l}\text { Qual a relação entre natureza, emoções e afetos e quais as } \\
\text { formas de resistência às dessensibilizações e alienações } \\
\text { no cotidiano? }\end{array}$ \\
\hline
\end{tabular}

Fonte: Autoras (2020)

Para cada uma das Oficinas temáticas foram previamente elaboradas dinâmicas e confeccionados materiais escritos, gráficos e fotográficos mediadores e disparadores de processos práxico-poiéticos. Nota-se que a opção estética das imagens utilizadas nos recursos audiovisuais mediadores produzidos pela equipe do projeto se situaram dentro da tradição artística surrealista, como as obras de Vladimir Kush, Jacek Yerka e Tommy Ingberg, por apostarem na imaginação, no onírico e na desconstrução dos padrões normativos, possibilitando experiências desestabilizadoras frente ao absurdo das imagens, abrindo brechas para metamorfoses pessoais e coletivas a partir do cotidiano.

Além disso, em todas as ações do projeto, o ambiente, atividades e recursos, enquanto espaço-tempo material e vivencial (Imagem 1), foram planejados de modo a propiciar aos participantes experiências sensoriais através dos elementos (água, terra, fogo e ar) e um despertar do imaginário (GOMES, 2015), favorecendo uma reflexão sobre suas tomadas de posição ético-políticas no cotidiano, os modos de pensar, agir, sentir e se relacionar com os outros e a natureza. Teve-se em conta a força da experiência estética, em sua relação com a ética, na provocação dos sentidos e da imaginação e que a atividade imaginária é precursora de toda e qualquer forma de atividade humana criativa (HERMANN, 2005, PINO, 2006). 
Imagem 1 - Ambiente e recursos materiais
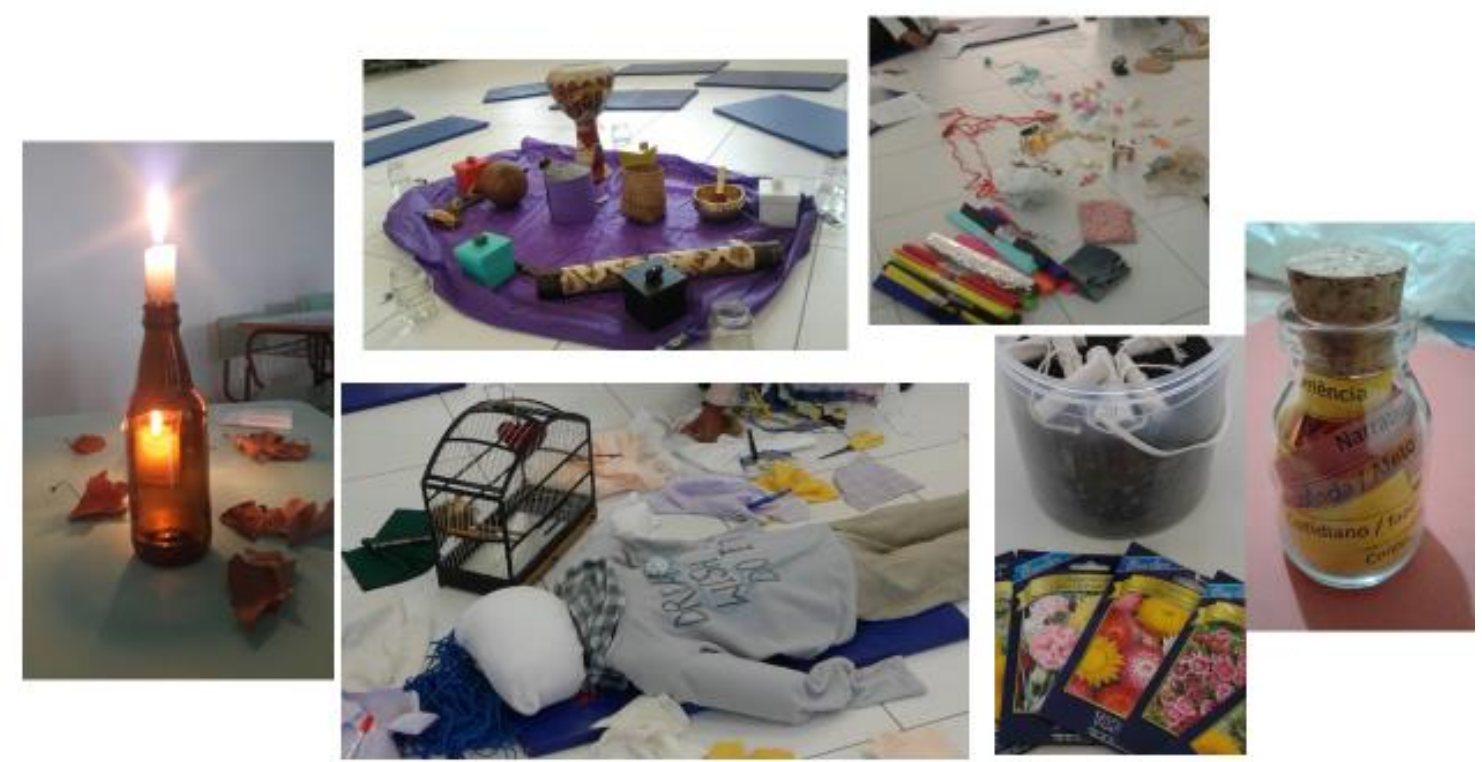

Fonte: Acervo de fotos do projeto (autoras)

Tendo em vista que a orientação metodológica balizadora do projeto foi a hermenêutico-dialética, os participantes foram protagonistas em todos os debates e rodas de conversa; realizando reflexões críticas sobre o próprio cotidiano, o tempo-espaço da realização das atividades, o uso e consumo de objetos e recursos, a partir de uma análise do modo de vida capitalístico. Além disso, apresentaram suas próprias táticas de resistência ao modo de vida normalizado, convencional e padronizado imposto pela sociedade contemporânea.

Nas rodas de conversa que encerravam as atividades, os participantes avaliaram positivamente as ações, pelo acolhimento e convivialidade propiciados, por terem sido um espaço de reflexão sobre si mesmos e de criação de estratégias para efetuarem mudanças que perceberam serem necessárias em seus cotidianos. Ainda, pela percepção da relação das atividades cotidianas com a preservação da natureza, garantia de direitos humanos e afirmação da diversidade/diferença. Nesse sentido, o projeto agregou à formação dos estudantes de Terapia Ocupacional ao criar espaços de encontro e troca de saberes com pessoas, grupos e coletivos envolvidos na defesa de direitos humanos.

Como pontos a melhorar, notou-se ser necessário ampliar as formas e estratégias de divulgação das ações de modo a contemplar ainda mais o público-alvo do projeto, 
sobretudo profissionais e também usuários de serviços assistenciais, aumentando o número de participantes nas atividades e a interlocução com movimentos de defesas de direitos.

Como produtos, foram gerados materiais didático-instrucionais para uso no curso de extensão, materiais audiovisuais para uso nas oficinas criativas e material de divulgação das ações realizadas pelo projeto. Também, foi criada uma página no Facebook, com administração das coordenadoras e extensionistas, para divulgação de eventos realizados pela UFPR, divulgação das ações do projeto, dos cartazes com link para inscrição de participantes em formulário, e outros eventos externos com temas afins.

Nota-se que o projeto contribuiu para experiência das extensionistas com a organização de eventos, confecção de material de apoio às ações desenvolvidas e também com a oportunidade de apresentação de trabalho por duas extensionistas no $16^{\mathrm{a}}$ Encontro de Extensão e Cultura (ENEC), durante a $9^{\text {a }}$ Semana de Ensino, Pesquisa e Extensão da UFPR - SIEPE/UFPR (2017).

Ademais, como ação de divulgação científica entre pares, as ações do projeto foram apresentadas, respectivamente, no formato oral e pôster no I Congreso Ibérico de Terapia Ocupacional: Integrando diversidades generando oportunidades (2018) e no XVI Encontro Nacional de Docentes de Terapia Ocupacional - ENDTO / V Seminário Nacional de Pesquisa em Terapia Ocupacional - SNPTO - Resistir e avançar: Terapia Ocupacional, democracia e diversidade na atualidade (2018).

\section{CONSIDERAÇÕES FINAIS}

Os objetivos do projeto de extensão inicialmente traçados foram alcançados, pois, para aos participantes, as atividades propostas se configuraram como espaços convivais e potenciais para troca de saberes e experiências, para experimentações ético-estéticopolíticas, fomentando a produção de novas configurações imaginativas sobre os modos de pensar, sentir, agir e se relacionar no mundo contemporâneo, e para o exercício do direito ao espaço urbano, em contraposição aos processos de exclusão sociocultural.

Além disso, as estratégias metodológicas utilizadas nas vivências partilhadas foram identificadas pelos participantes como estratégias replicáveis em suas ações profissionais, podendo ser realizadas em diferentes contextos clínico-assistenciais, 
educativos, culturais e sócio-comunitários. Pois, além de servir como metodologia de investigação em Terapia Ocupacional, a orientação hermenêutico-dialética na prática assistencial pode fundamentar a criação de espaços de encontro convivais, dando abertura à ressignificações e à tecituras de novos modos de vida cotidianos.

Considerando a indissociabilidade ensino-pesquisa-extensão, o desenvolvimento das ações do projeto colaborou para uma formação crítico-reflexiva dos estudantes frente à vida cotidiana e a diversidade dos modos de vida, a interação dialógica entre diferentes grupos e coletivos (da comunidade interna e externa à Universidade) e proporcionaram também o aprofundamento dos conteúdos relativos aos fundamentos teóricometodológicos e epistemológicos dos Cursos de Terapia Ocupacional (integral e noturno), colaborando com a efetivação do projeto pedagógico em implantação.

\section{AGRADECIMENTOS}

Agradecemos às extensionistas voluntárias Thalita Katiuscia Picoli Vicente e Francinne de Oliveira Lima Kohls (período 2017-2018), Hellen Kertischka Batista de Lima e Kessilin Kawana Rufino Batista (2018).

\section{REFERENCIAS}

ACOSTA A. O Bem Viver: uma oportunidade para imaginar outros mundos. Tradução de Tadeu Breda. São Paulo: Autonomia Literária/Elefante, 2016. 264 p

BONDÍA, J.L. (2002). Notas sobre a experiência e o saber de experiência. Revista Brasileira de Educação, (19), 20-28. Disponível em: https://doi.org/10.1590/S141324782002000100003. Acesso em 14 de out 2020.

BRAGA, G. B.; FIUZA, A. L. C.; REMOALDO, P. C. A. O conceito de modo de vida: entre traduções, definições e discussões. Sociologias, Porto Alegre, ano 19, no 45, mai/ago 2017, p. 370-396. Disponível em: https://doi.org/10.1590/15174522-019004521. Acesso em 14 de out 2020.

CASTORIADIS, C. A Instituição Imaginária da Sociedade. Rio de Janeiro: Paz e Terra, 1982. 
CASTRO, E.D.; LIMA, E.M.F.A.; INFORSATO, E.A.; ANGELI, A. A. C. Formação em Terapia Ocupacional na Interface das Artes e da Saúde: a experiência do PACTO. Rev Ter Ocup Univ São Paulo. v. 20, p. 149-156, 2009. Disponível em: https://pesquisa.bvsalud.org/portal/resource/pt/lil-657226 Acesso em 14 de out 2020.

CERTEAU, M. A invenção do cotidiano: artes de fazer. Petrópolis, Vozes, 2014.

COSTA, L. C. A estrutura da vida cotidiana: uma abordagem através do pensamento lukacsiano. Emancipação, 1(1): 33-57, 2001. Disponível em: https://revistas2.uepg.br/index.php/emancipacao/article/view/22. Acesso em 14 de out 2020.

FERIGATO, S.H.; SILVA, C.R.; LOURENÇO, G.R. A convivência e o com-viver como dispositivos para a Terapia Ocupacional. Cadernos de Terapia Ocupacional da UFSCar, v. 24, p. 849-857, 2016. Disponível em: https://doi.org/10.4322/01044931.ctoEN0735. Acesso em 14 de out 2020.

FONSECA, T. M. G.; et. al. O cotidiano frente à experiência liminar. Fractal: Revista de Psicologia, 30(2), 180-188, 2018. Disponível em: https://doi.org/10.22409/1984-0292/v30i2/5548._Acesso em 14 de out 2020

FOUCAULT, M. Microfísica do poder. 19 ed. Tradução Roberto Machado. Rio de Janeiro: Graal, 2000.

O nascimento da biopolítica. Tradução de Eduardo Brandão. São Paulo: Martins Fontes, 2008.

FURTADO, E.A.; FISCHER, M.C.B. (2011). Método da escavação em terapia ocupacional: um dispositivo dinâmico a três polos? Trabalho, Educação e Saúde, 9 (Suppl. 1), 175-199. Disponível em: http://dx.doi.org/10.1590/S198177462011000400009. Acesso em 14 de out 2020.

GAJARDO, M. Ivan Illich. (trad. e org.: José Eustáquio Romão). Recife: Fundação Joaquim Nabuco, Editora Massangana, 2010.

GALHEIGO, S. O cotidiano na terapia ocupacional: cultura, subjetividade e contexto histórico-social. Rev de Ter Ocup da Univ de São Paulo, 14(3), 104-109, 2003. 
GOMES, R. Pesquisa qualitativa em saúde. São Paulo: Instituto Sírio-Libanês de Ensino e Pesquisa, 2014.

GOMES, M.B. Gaston Bachelard: e a metapoética dos quatro elementos. Rev Estética. 2015;(11):1-9.

HELLER, A. O cotidiano e a história. São Paulo, Paz e Terra, 7ª ed., 2004.

HERMANN, N. Ética e estética: a relação quase esquecida. Porto Alegre: EDIPUCRS, 2005.

LACOMBE, M. S. M. Os fundamentos marxistas de uma sociologia do cotidiano. Outubro, n.17, 2008.

LANTZ, P. La Poièsis de la Praxis Henri Lefebvre. In: L'Homme et la société, n. 104, Anthropolgie de l'espace habité. pp. 111-120, p. 1992.

LATOUCHE, S. O decrescimento como condição de uma sociedade convivial. Cadernos IHU Ideias, São Leopoldo, v. 4, n. 56, 2006. Convivialidade e descrescimento. Cadernos IHU. Ano 10, nº 166, 2012.

MAFFESOLI, M. No fundo das aparências. Rio de Janeiro, Vozes, 2010a. Saturação. São Paulo: Iluminuras: Itaú Cultural, 2010b.

MELLO, L. C. Nise da Silveira, caminhos de uma psiquiatra rebelde. Rio de Janeiro: Edições Automática/Hólos, 2014. 367 pp

MOREIRA, A. B. Nietzsche e Espinosa: fundamentos para uma terapêutica dos afetos. Cadernos Espinosanos, (24), 141-165, 2010.

; ZIMMERMANN, A. B. Perspectivas sobre o cotidiano, formas e modos não-convencionais de vida. 2017. (Relatório) Curitiba: Coordenadoria de Extensão da Universidade Federal do Paraná, 2017.

; PINTO, L. M. Cotidiano, convivialidade e modos não convencionais de vida. (Relatório) Curitiba: Coordenadoria de Extensão da Universidade Federal do Paraná, 2018. 
MINAYO, M. C. S. Hermenêutica-dialética como caminho do pensamento social. In: MINAYO, M. C. S; DESLANDES, S. F. (Org). Caminhos do pensamento: epistemologia e método. Rio de Janeiro, Fiocruz, p. 83-107, 2002.

NETTO, J. P.; CARVALHO, M. C. B. Cotidiano: conhecimento e crítica. $7^{\mathrm{a}}$ ed. São Paulo: Cortez, 2007.

PASSOS, E; BARROS, R.B. Clínica, política e as modulações do capitalismo. Rev. Lugar Comum, Rio de Janeiro, n. 19-20, p. 159-171, jan./jun. 2004. Disponível em: https://repositorio.observatoriodocuidado.org/handle/handle/1274. Acesso em 14 de out 2020.

PINO, A. A produção imaginária e a formação do sentido estético. Reflexões úteis para uma educação humana. Pro-Posições, v. 17, n. 2 (50) - maio/ago. 2006. Disponível em: https://periodicos.sbu.unicamp.br/ojs/index.php/proposic/article/view/8643628. Acesso em 14 de out 2020.

SILVA, C.R., POELLNITZ, J.C.V. Atividades na formação do terapeuta ocupacional. Rev Ter Ocup Univ São Paulo. 2015 jan./abr.;26(1):74-82. Disponível em: https://doi.org/10.11606/issn.2238-6149.v26i1p74-82. Acesso em 14 de out 2020.

SOUSA FILHO, A. Michel de Certeau: Fundamentos de uma sociologia do cotidiano. Sociabilidades. São Paulo, v.2, p.129 - 134, 2002.

VANALI, A. C. Agnes Heller e Michel de Certeau: propostas de análise sobre a vida cotidiana. Vozes, Pretérito \& Devir. 2015;IV(1):110-25. Disponível em: http://revistavozes.uespi.br/ojs/index.php/revistavozes/article/view/76. Acesso em 14 de out 2020 .

VAZQUEZ, A. S. Filosofia da Práxis. 2a edição. Rio de Janeiro: Editora Paz e Terra, 1977.

ZIMMERMANN et.al. Reformulação curricular dos cursos de Terapia Ocupacional: resultados e desafios de um percurso. Interface (Botucatu), Botucatu, v. 23, e180276, 2019. Disponível em: https://www.scielo.br/scielo.php?pid=S141432832019000100217\&script=sci_abstract\&tlng=pt 
DOI: http://dx.doi.org/10.5380/ef.v0i20

Recebido em: 18 de outubro de 2020

Aceito em: 16 de dezembro de 2020 